Gut, 1979, 20, 971-976

\title{
Cigarette smoking, chronic peptic ulceration, and pepsin 1 secretion
}

\author{
V. WALKER' ${ }^{1}$ AND W. H. TAYLOR \\ From the Department of Chemical Pathology, Liverpool Area Health Authority (T), Royal Liverpool \\ Hospital, Liverpool
}

SUMMARY The relationship between the secretion of pepsin 1 (the most electronegative of the pepsins), and the smoking habits of 219 patients has been investigated. Significantly more cigarette smokers with peptic ulceration (72.5\%) secreted pepsin 1 in greater than trace amounts after pentagastrin or histamine than did non-smokers with ulceration $(51 \cdot 2 \%)$. Differences of a similar order were found for men with duodenal ulcer, women with duodenal ulcer, and all patients with gastric ulcer, but the difference was statistically significant only for men with duodenal ulcer. Significantly more patients with peptic ulcer smoking six to 15 cigarettes/day secreted moderate or high concentrations of pepsin 1 than did heavier smokers or non-smokers. There was no significant association between cigarette smoking and pepsin 1 secretion among 74 patients without ulceration. Maximal acid output was not significantly related to smoking in any group studied. The findings add to the increasing body of evidence linking pepsins and pepsin 1 with the pathogenesis of peptic ulceration.

Epidemiologically there is a relationship between cigarette smoking and peptic ulceration, which has been demonstrated in retrospective studies (Barnett, 1927; Trowell, 1934; Mills, 1950; Allibone and Flint, 1958 ) in cross-sectional studies (Edwards et al., 1959; Monson, 1970) and in prospective surveys (Doll and Hill, 1956; Hammond and Horn, 1958; Dorn, 1959; Dunn et al., 1960a, b; Best et al., 1961 ; Doll and Hill, 1964; Hammond, 1964; Doll and Peto, 1976). The association is probably stronger for gastric than for duodenal ulceration (Hammond and Horn, 1958; Dorn, 1959; Hammond, 1964). Cessation of smoking leads to rapid improvement in the symptoms of peptic ulceration (Gray, 1929; Batterman and Ehrenfeld, 1949) and accelerates ulcer healing (Doll et al., 1958). In one retrospective study, however, an adverse effect of cigarette smoking on the rate of ulcer healing was not confirmed (Herrmann and Piper, 1973).

In response to histamine, patients with peptic ulceration secrete pepsin 1 , the most electronegative of the pepsins, significantly more often and in greater amount than do control subjects without

\footnotetext{
${ }^{1}$ Address for correspondence: Dr. V. Walker, Department of Chemical Pathology, The University of Southampton, Southampton General Hospital, Tremona Road, Southampton SO9 4XY.
}

Received for publication 16 May 1979 ulceration (Taylor, 1970). The association is stronger for gastric ulceration. Moreover, the secretion of pepsin 1 is decreased in patients with peptic ulceration responding well to treatment with carbenoxolone (Walker and Taylor, 1975). The question therefore arises as to whether secretion of this apparently 'ulcer-associated' pepsin is increased in cigarette smokers.

\section{Methods}

Patients who had augmented histamine tests (Kay, 1953) carried out at the Liverpool Royal Infirmary from September 1965 to March 1970, or who underwent augmented histamine or pentagastrin (Baron, 1970) tests from October 1970 to October 1974, were studied. These tests were carried out as part of the investigation of gastrointestinal symptoms or, in a small proportion of cases, of anaemia. All histamine and pentagastrin tests received in the laboratory during these periods were analysed. For each test, the hydrogen ion content of the stimulated secretions was determined, and the maximal acid output (MAO) calculated as the hydrogen ions secreted in 60 minutes after injection of gastric stimulant $(\mathrm{mmol} / \mathrm{h})$. The secretions were then pooled, and an aliquot analysed for pepsins by agar gel electrophoresis (Etherington and Taylor, 1969). Photographs of the electrophoretograms were 
examined by two observers, who made a semiquantitative assessment of the amount of pepsin 1 present -a fully quantitative method is not yet available. Pepsin 1 was assigned a grade of $\mathbf{0}$ for no activity to ++++ for maximal activity. By reference to swine pepsin standards run electrophoretically on agar gels, grade ++++ was roughly equivalent to $50 \mu \mathrm{g} / \mathrm{ml}$ pepsin, +++ to $16.7 \mu \mathrm{g} / \mathrm{ml}$, ++ to $4 \mu \mathrm{g} / \mathrm{ml}$, + to $1.5 \mu \mathrm{g} / \mathrm{ml}$, and 'trace' to 0.7 $\mu \mathrm{g} / \mathrm{ml}$.

Patients were classified according to gastrointestinal disease on the basis of barium meal, endoscopic, and, where available, subsequent operative findings. Patients were excluded if a clinical diagnosis was not supported by unequivocal findings, or if they had pernicious anaemia, gastric neoplasm, previous gastric surgery, or treatment with carbenoxolone up to the time of the acid output test. Information about the smoking habits of the patients, at the time of the test, was obtained from the hospital case sheets. Patients smoking pipes or cigars and not cigarettes, were excluded. The pepsin 1 grading, the smoking habits, and the clinical diagnosis were ascertained independently for each patient, and the three pieces of information were not associated until the study was complete.

Two hundred and nineteen patients were finally included in the study-98 from October 1965 to March 1970, and 121 from October 1970 to October 1974. 142 patients were cigarette-smokers, and 77 were non-smokers. One hundred and forty-five patients had peptic ulceration; 103 men; 42 women). Of the remaining 74 patients, 36 (comprising the 'gastric symptoms' group) had symptoms of peptic ulceration, but no evidence of ulcer on barium meal and/or endoscopic examinations. The remaining 38 patients form the 'miscellaneous group' and had a variety of conditions including diarrhoea, steatorrhoea, and anaemia (excluding pernicious anaemia). It should be stressed that the 'miscellaneous' and 'gastric symptoms' groups of patients were studied in their own right and were not intended as controls for the patients with ulceration: they cannot be considered as being normal individuals.

\section{Results}

INCIDENCE OF PEPSIN 1 SECRETION

(t and over)

Patients with peptic ulceration (Table 1)

Significant differences were found for the incidence of pepsin 1 secretion between smokers and nonsmokers as follows:

1 All patients with peptic ulceration $51.2 \%$ of non-smokers secreted + or more of pepsin 1 compared with $72.5 \%$ of smokers $(P<0.02)$, and with
$73.9 \%$ of those who smoked five or more cigarettes per day $(\mathrm{P}<0.01)$.

2 Men with peptic ulceration $52.0 \%$ of nonsmokers compared with $73.1 \%$ of smokers $(P<0.05)$, and with $75.0 \%$ of men smoking five or more cigarettes/day $(\mathrm{P}<0.05) ; 28.2 \%$ of the smokers had gastric ulceration compared with $28.0 \%$ of non-smokers.

3 All patients with duodenal ulceration $48.3 \%$ of non-smokers compared with $72.4 \%$ of smokers $(P=0.02)$, and with $72.5 \%$ of those smoking five or more cigarettes/day $(\mathrm{P}<0.05)$.

4 Men with duodenal ulceration $50.0 \%$ of nonsmokers compared with $75.0 \%$ of smokers $(P<0.05)$, and with $75.5 \%$ of those smoking five or more cigarettes/day $(\mathrm{P}<0.05)$.

Although differences between the incidences of pepsin 1 secretion by non-smokers and smokers were not of statistical significance among the women with peptic ulceration, women with duodenal ulceration, and all patients with gastric ulceration, it is apparent (Table 1) that the differences were of a similar order to those observed in the results given above. Probably the differences would have become statistically significant had more patients been studied.

\section{Patients without peptic ulceration (Table 1)}

No significant differences emerged between the incidences of pepsin 1 secretion among smokers and non-smokers, respectively, in the 'miscellaneous' and 'gastric symptoms' groups of patients. When the incidence among all male non-smokers without ulceration (miscellaneous and 'gastric symptoms' groups combined) was compared with that among all male smokers or male smokers of five or more cigarettes/day, respectively, no significant differences emerged. Similarly, the differences between female smokers and non-smokers were not statistically significant.

\section{Among smokers (Table 1)}

The incidence of pepsin 1 secretion among all smokers with ulcer $(72.5 \%)$ was significantly higher $(\mathrm{P}<0.05)$ than among the combined groups of smokers without ulcer $(55 \cdot 0 \%)$.

MEAN AGES OF GROUPS OF PATIENTS

The mean ages were similar for those groups of patients for which a significant difference in the incidence of pepsin 1 secretion was observed (Table 2). Non-smokers with gastric ulceration had a higher mean age than smokers $(58.4$ years compared with 50.2 years), and this reflected the inclusion of seven female non-smokers who had a mean age of 69.6 years. 
Table 1 Pepsin 1 secretion (+ and over) according to smoking habit of 145 patients with and 74 patients without peptic ulceration

\begin{tabular}{|c|c|c|c|c|c|c|c|c|c|}
\hline \multirow[t]{3}{*}{ Patients } & \multicolumn{3}{|c|}{ Non-smokers } & \multicolumn{3}{|c|}{ All cigarette smokers } & \multicolumn{3}{|c|}{ Five or more cigarettes/day } \\
\hline & \multirow[t]{2}{*}{ Total } & \multicolumn{2}{|c|}{ With pepsin 1} & \multirow[t]{2}{*}{ Total } & \multicolumn{2}{|c|}{ With pepsin 1} & \multirow[t]{2}{*}{ Total } & \multicolumn{2}{|c|}{ With pepsin 1} \\
\hline & & (No.) & $(\%)$ & & (No.) & $(\%)$ & & (No.) & $(\%)$ \\
\hline \multicolumn{10}{|l|}{ Peptic ulcer } \\
\hline All patients & 43 & 22 & $51 \cdot 2$ & $102 * \dagger$ & 74 & $72 \cdot 5$ & $92 *$ & 68 & 73.9 \\
\hline Men & 25 & 13 & $52 \cdot 0$ & $78 *$ & 57 & $73 \cdot 1$ & $72 *$ & 54 & $75 \cdot 0$ \\
\hline Women & 18 & 9 & $50 \cdot 0$ & 24 & 17 & $70 \cdot 8$ & 20 & 14 & $70 \cdot 0$ \\
\hline \multicolumn{10}{|l|}{ Duodenal ulcer } \\
\hline All patients & 29 & 14 & $48 \cdot 3$ & $76^{*}$ & 55 & $72 \cdot 4$ & $69 *$ & 50 & $72 \cdot 5$ \\
\hline Men & 18 & 9 & 50.0 & $56^{*}$ & 42 & $75 \cdot 0$ & $53^{*}$ & 40 & $75 \cdot 5$ \\
\hline Women & 11 & 5 & $45 \cdot 5$ & 20 & 13 & $65 \cdot 0$ & 16 & 10 & $62 \cdot 5$ \\
\hline \multicolumn{10}{|l|}{ Gastric ulcer } \\
\hline All patients & 14 & 8 & $57 \cdot 1$ & 26 & 19 & $73 \cdot 1$ & 23 & 18 & $78 \cdot 3$ \\
\hline \multicolumn{10}{|l|}{ No ulcer } \\
\hline All patients & 34 & 20 & $58 \cdot 8$ & 40 & 22 & $55 \cdot 0$ & 37 & 22 & 59.5 \\
\hline Men & 16 & 10 & $62 \cdot 5$ & 23 & 15 & $65 \cdot 2$ & 22 & 15 & $68 \cdot 2$ \\
\hline Women & 18 & 10 & $55 \cdot 6$ & 17 & 7 & $41 \cdot 2$ & 15 & 7 & $46 \cdot 7$ \\
\hline Miscellaneous: all & 21 & 12 & $57 \cdot 1$ & 17 & 10 & $58 \cdot 8$ & 15 & 10 & $66 \cdot 7$ \\
\hline Gastric symptoms: all & 13 & 8 & $61 \cdot 5$ & 23 & 12 & $52 \cdot 2$ & 22 & 12 & $54 \cdot 5$ \\
\hline
\end{tabular}

* Difference from non-smokers statistically significant.

†Difference from non-ulcer smokers statistically significant.

Table 2 Mean ages of smokers and non-smokers in study

\begin{tabular}{|c|c|c|c|c|}
\hline & \multicolumn{2}{|c|}{ Smokers } & \multicolumn{2}{|c|}{ Non-smokers } \\
\hline & No. & $\begin{array}{l}\text { Mean age } \\
(y r)\end{array}$ & No. & $\begin{array}{l}\text { Mean age } \\
(y r)\end{array}$ \\
\hline $\begin{array}{l}\text { All patients with ulcer } \\
\text { Gastric ulcer-all patients } \\
\text { Duodenal ulcer-all patients } \\
\text { Duodenal ulcer-men } \\
\text { Duodenal ulcer-women }\end{array}$ & $\begin{array}{l}102^{*} \dagger \\
26 \\
76^{*} \\
56^{*} \\
20\end{array}$ & $\begin{array}{l}45 \cdot 1 \\
50 \cdot 2 \\
43 \cdot 4 \\
41 \cdot 3 \\
49 \cdot 3\end{array}$ & $\begin{array}{l}43 \\
14 \\
29 \\
18 \\
11\end{array}$ & $\begin{array}{l}46 \cdot 0 \\
58 \cdot 4 \\
40 \cdot 1 \\
39 \cdot 1 \\
41 \cdot 7\end{array}$ \\
\hline $\begin{array}{l}\text { All patients without ulcer } \\
\text { 'Gastric symptoms'—all patients } \\
\text { Miscellaneous-all patients }\end{array}$ & $\begin{array}{l}40 \\
23 \\
17\end{array}$ & $\begin{array}{l}42 \cdot 4 \\
36 \cdot 7 \\
50 \cdot 1\end{array}$ & $\begin{array}{l}34 \\
13 \\
21\end{array}$ & $\begin{array}{l}51 \cdot 2 \\
53 \cdot 6 \\
49 \cdot 7\end{array}$ \\
\hline
\end{tabular}

*Incidence of pepsin 1 secretion significantly different from non-smokers.

IIncidence of pepsin 1 secretion significantly different from smokers without ulcer.

PEPSIN 1 SECRETION AND NUMBER OF

CIGARETTES SMOKED PER DAY

Patients with peptic ulceration (Table 3)

The incidence of pepsin 1 secretion graded + or more was very similar among patients smoking one to five, six to 15 , and 16 or more cigarettes/day, respectively, and in the cases of the two heavier smoking groups differed significantly from that among non-smokers $(P<0.05$; and $P<0.05$, respectively). When the incidences of secretion of higher amounts of pepsin 1 ( ++ or more) are compared, that of patients smoking six to 15 cigarettes/day was significantly higher than that of the non-smokers $(P<0.001)$, and of those smoking 16 or more cigarettes/day $(P<0.05)$. The difference between nonsmokers and smokers of 16 or more cigarettes/day was not significant $(0 \cdot 2>P>0 \cdot 1)$. A slightly higher proportion of patients smoking six to 15 cigarettes/
Table 3 Patients with peptic ulceration: relationship of pepsin 1 secretion to number of cigarettes smoked daily

\begin{tabular}{|c|c|c|c|c|c|}
\hline \multirow{3}{*}{$\begin{array}{l}\text { Smoking habit } \\
\text { (cigarettes/day) }\end{array}$} & \multirow{3}{*}{$\begin{array}{l}\text { No. in } \\
\text { group }\end{array}$} & \multicolumn{4}{|c|}{ Pepsin 1} \\
\hline & & \multicolumn{2}{|c|}{ tand over } & \multicolumn{2}{|c|}{++ and over } \\
\hline & & $(\mathrm{No})$. & (\%) & (No.) & $(\%)$ \\
\hline $\begin{array}{l}\text { Non-smokers } \\
1-5 \\
6-15 \\
16+\end{array}$ & $\begin{array}{l}43 \\
14 \\
44 \\
44\end{array}$ & $\begin{array}{l}22 \\
10 \\
32 \\
32\end{array}$ & $\begin{array}{l}51 \cdot 2 \\
71 \cdot 4 \\
72 \cdot 7 \\
72 \cdot 7\end{array}$ & $\begin{array}{c}5 \\
2 \\
19 * \\
10\end{array}$ & $\begin{array}{l}11 \cdot 6 \\
14 \cdot 3 \\
43 \cdot 2 \\
22 \cdot 7\end{array}$ \\
\hline
\end{tabular}

*Significantly different from non-smokers and smokers of 16 or more cigarettes/day.

day had duodenal ulceration $(79.5 \%)$ than had the heavier smokers $(68 \cdot 2 \%)$.

Patients without peptic ulceration

The incidence of pepsin 1 secretion in amounts of + 
and over was very similar for non-smokers, smokers of six to 15 , and of 16 or more cigarettes/day $(58.8 \%$, $64.7 \%$, and $64.3 \%$ respectively), as was the incidence of secretion in amounts of ++ and over $(26.5 \%, 23.5 \%$, and $21.4 \%$, respectively).

\section{Maximal acid output (MAO) in non-smokers and smokers}

When men with duodenal ulceration were considered, the mean MAO of 13 non-smokers was $23.15 \mathrm{mmol} / \mathrm{h}$, SD 13.69 , and that of 45 smokers was $26.72 \mathrm{mmol} / \mathrm{h}$, SD $10.97(\mathrm{P}>0.3 ; \mathrm{n}=56)$. There was no significant difference between the proportion of smokers and non-smokers who had MAO greater than 20,30 , or $40 \mathrm{mmol} / \mathrm{h}$ respectively, whether all cigarette smokers were considered, or only those smoking more than five cigarettes/day. When women with duodenal ulceration were considered, the mean MAO of seven non-smokers was $14.03 \mathrm{mmol} / \mathrm{h}, \mathrm{SD} 12.59$, and that of 17 smokers was $18.83 \mathrm{mmol} / \mathrm{h}, \mathrm{SD} 9.03(\mathrm{P}>0 \cdot 3, \mathrm{n}=22)$.

\section{Discussion}

The smoking habits of our patients were ascertained retrospectively. The limited accuracy of information obtained in this way is well-known and the effect of such limitations upon our conclusions must be considered.

Smokers tend to underestimate their cigarette consumption, so that, in general, this limitation would obscure differences between smokers and non-smokers, rather than the reverse, giving added significance to the observed differences in pepsin 1 secretion. As we have, however, accepted only those records in which a definite number of cigarettes smoked daily is stated, the important separation into smokers and non-smokers is likely to be accurate. The number of cigarettes smoked may be less accurate, but it would be surprising if such an inaccuracy could cause to be spurious the observation that more of those smoking six to 15 cigarettes daily secreted pepsin than did heavier smokers; and this observation has an important parallel in the incidence of peptic ulcer in relation to smoking, as disucssed later. It must be remembered, too, that the initial observations connecting smoking with peptic ulcer were made from retrospective studies. Such studies also have the considerable advantage of being quite free from observer bias. Our conclusions have, there fore, the same degree of validity that is accorded to retrospective studies in this and other fields and will, we hope, lead others to investigate prospectively the hypothesis that arises.

There appear to be two possible explanations of the observed relationship between smoking, peptic ulceration, and pepsin 1 secretion. The first is that nicotine, or some other agent absorbed during cigarette smoking, stimulates pepsin 1 secretion, the second is that pepsin 1 secretion, peptic ulceration, and smoking are associated, but not by a 'cause and effect' relationship.

An acute, direct, effect of nicotine on pepsin 1 secretion can probably be ruled out. We cannot exclude the possiblity that some of the smokers (both with and without ulcer) would have smoked between waking and having the histamine or pentagastrin test, but among all smokers significantly more of those with ulcer secreted pepsin 1 than did those without (Table 1), and the pepsin 1 secretion of the latter group was almost identical with that of the non-smokers without ulcer.

A chronic long-term effect of nicotine, or some other agent in tobacco-smoke, cannot be fully excluded, although if this were the case, it would be expected that the secretion of pepsin 1 by smokers without peptic ulceration would be greater than that by non-smokers, whereas we observed no significant difference. A long-term effect might be to produce some structural change in the gastric mucosa, such as an increase in the number of pepsin-secreting cells. A possible future approach would be to study serum pepsinogen levels in relation to the smoking habit. The absence of any increase in maximal acid output in smokers with peptic ulceration, as compared with non-smokers, suggests very strongly, however, that the known proliferation of parietal cells in some patients with duodenal ulcer is not a long-term effect of smoking.

In contrast with a long-term action of nicotine, the hypothesis has been advanced (Lilienfeld, 1959) that the tendencies to smoke and to develop peptic ulceration reflect some underlying feature of the ulcer-susceptible individual; to these tendencies, on this hypothesis, must now be added that of secreting excessive amounts of pepsin 1. One might speculate that in susceptible individuals there is an increased 'secretory drive' on the gastric mucosa, which may be vagal, since pepsin 1 secretion occurs in man in response to vagal stimulation and to stress (Walker and Taylor, 1976). However, one is then left with the problem of explaining why ulcers should develop in non-smokers and in some patients who do not have an increased incidence of pepsin 1 secretion. In future studies it would be desirable to take into account not only pepsin 1 secretion, but also other aetiological factors such as secretor status and blood group.

Doll and his colleagues (Doll and Hill, 1964; Doll and Peto, 1976) found a higher incidence of peptic ulceration among their middle smoking group (smoking 15-24 cigarettes/day), a curious finding for 
Table 4 Pepsin 1 secretion (++ or more): smoking habits as classified by Doll et al. $(1956,1964,1976)$

\begin{tabular}{|c|c|c|c|c|}
\hline \multirow[t]{2}{*}{ Patients } & \multicolumn{4}{|c|}{ Cigarettes smoked per day } \\
\hline & 0 & $1-14$ & $15-24$ & 25 or more \\
\hline $\begin{array}{l}\text { All patients: } \\
\text { Total in group } \\
\text { Secreting pepsin } 1 \text { (no.) } \\
\text { (\%) }\end{array}$ & $\begin{array}{l}77 \\
14 \\
18 \cdot 2\end{array}$ & $\begin{array}{l}68 \\
22^{*} \\
32 \cdot 4\end{array}$ & $\begin{array}{l}54 \\
13 \\
24 \cdot 1\end{array}$ & $\begin{array}{c}20 \\
5 \\
25 \cdot 0\end{array}$ \\
\hline $\begin{array}{l}\text { Patients with peptic ulceration: } \\
\text { Total in group } \\
\text { Secreting pepsin } 1 \text { (no.) } \\
\text { (\%) }\end{array}$ & $\begin{array}{c}43 \\
5 \\
11 \cdot 6\end{array}$ & $\begin{array}{l}49 \\
16^{*} \\
32 \cdot 7\end{array}$ & $\begin{array}{l}41 \\
12 * \\
29 \cdot 3\end{array}$ & $\begin{array}{c}12 \\
3 \\
25 \cdot 0\end{array}$ \\
\hline Patients with peptic ulcer (\%) & 55.8 & $72 \cdot 1$ & 75.9 & $60 \cdot 0$ \\
\hline
\end{tabular}

*Significantly different from non-smokers.

which there is no ready physiological basis. In this context, therefore, the observation that significantly more patients with peptic ulceration of the middle smoking group of the present study (smoking six to 15 cigarettes/day) secreted pepsin 1 in increased amount, might be relevant. To investigate this further, patients were grouped according to the smoking classification of Doll et al. (Table 4). The highest incidence of pepsin 1 secretion in amounts of ++ and over among patients with peptic ulceration now occurs in the group smoking one to 14 cigarettes/day, as it does among all the patients in the study. The differences in incidence between the three categories of smokers were small, however, and not statistically significant. The incidence of pepsin 1 secretion of this concentration does not, therefore, mirror precisely, and would not provide an immediate explanation for, the distribution of peptic ulceration found by Doll et al. Yet it is of interest that the expected increase in pepsin 1 secretion with increasing numbers of cigarettes smoked daily, like that of peptic ulceration, does not occur.

The association of smoking and peptic ulceration is well documented but is statistically relatively slight. Attempts to explain the association by showing that smoking (or nicotine administration) produces an increased secretion of total pepsins (Bennett, 1972; Whitecross, et al., 1974) or of hydrogen ions (Toon, et al., 1951; Bennett, 1972; Fung and Tye, 1973; Whitecross, et al., 1974) have for the most part yielded negative results. The present observations that pepsin 1 secretion is increased in smokers with peptic ulceration would provide a possible explanation for the (relatively weak) association, if pepsin 1 were to have a role in the pathogenesis of peptic ulcer. Other evidence for such a role includes the observations that pepsin 1 secretion is increased in gastric ulceration, in contrast with a normal secretion of total pepsins and of hydrogen ions, and is reduced in patients who respond clinically to carbenoxolone (Walker and
Taylor, 1975), whereas hydrogen ion secretion is not reduced. Peptic ulceration is now believed to have a multifactorial aetiology, and the factor of prime importance in individual patients is likely to differ. Since pepsin 1 is present in situations in which the traditional ulcerogenic hypotheses associated with hydrogen ions or with total pepsins cannot be invoked, this enzyme should be included among possible aetiological factors.

\section{References}

Allibone, A., and Flint, F. J. (1958). Bronchitis, aspirin, smoking and other factors in the aetiology of peptic ulcer. Lancet, 2 179-182.

Barnett, C. W. (1927). Tobacco smoking as a factor in the production of peptic ulcer and gastric neurosis. Boston Medical and Surgical Journal, 197, 457-459.

Baron, J. H. (1970). The clinical use of gastric function tests. Scandinavian Journal of Gastroenterology, 5 suppl. 6, 9-46.

Batterman, R. C., and Ehrenfeld, I. (1949). The influence of smoking upon the management of the peptic ulcer patient. Gastroenterology, 12, 575-585.

Bennett, J. R. (1972). Smoking and the gastrointestinal tract. Gut, 13, 658-665.

Best, E. W. R., Josie, G. H., and Walker, C. B. (1961). A Canadian study of mortality in relation to smoking habits, a preliminary report. Canadian Journal of Public Health, 52, 99-106.

Doll, R., and Hill, A. B. (1956). Lung cancer and other causes of death in relation to smoking. A second report on the mortality of British doctors. British Medical Journal, 2, 1071-1081.

Doll, R., and Hill A. B. (1964). Mortality in relation to smoking: ten years' observations of British doctors. British Medical Journal, 1, 1399-1410, and 1460-1467.

Doll, R., Jones, F. A., and Pygott, F. (1958). Effect of smoking on the production and maintenance of gastric and duodenal ulcers. Lancet, 1, 657-662.

Doll, R., and Peto, R. (1976). Mortality in relation to smoking: 20 years' observations on male British doctors. British Medical Journal, 2, 1525-1536.

Dorn, H. F. (1959). Tobacco consumption and mortality from cancer and other diseases. Public Health Reports, 74, 581-593, cited in U.S. Department of Health, Education and Welfare (1964) Smoking and Health. van Nostrand: New York.

Dunn, J. E. Jr, Buell,P., and Breslow, L. (1960a). California State Department of Public Health, special report to the Surgeon General's Advisory Committee on smoking and health cited in U.S. Department of Health, Education and Welfare (1964) Smoking and Health. van Nostrand: New York.

Dunn, J. E. Jr, Linden, G., and Breslow, L. (1960). Lung cancer mortality experience of men in certain occupations in California. American Journal of Public Health, 50, 1475-1487.

Edwards, F., McKeown, T., and Whitfield, A. G. W. (1959). Association between smoking and disease in men over sixty. Lancet, 1, 196-200. 
Etherington, D. J., and Taylor, W. H. (1969). The pepsins of normal human gastric juice. Biochemical Journal, 113, 663-668.

Fung, Wye-Poh, and Tye, Cho-Yook (1973). Effect of smoking on gastric acid secretion. Australian and New Zealand Journal of Medicine, 3, 251-254.

Gray, I. (1929). Tobacco smoking and gastric symptoms. Annals of Internal Medicine, 3, 267-277.

Hammond, E. C. (1964). Smoking in relation to mortality and morbidity: findings in first thirty-four months of follow-up in a prospective study started in 1959. Journal of the National Cancer Institute, 32, 1161-1188.

Hammond, E. C., and Horn, D. (1958). Smoking and death rates-report on forty-four months of follow-up of 187,783 men. Journal of the American Medical Association, 166, 1159-1172, and 1294-1308.

Herrmann, R. P. and Piper, D.W. (1973). Factors influencing the healing rate of chronic gastric ulcer. American Journal of Digestive Disease, 18, 1-6.

Kay, A. W. (1953). Effect of large doses of histamine on gastric secretion of $\mathrm{HCl}$. An augmented histamine test. British Medical Journal, 2, 77-80.

Lilienfeld, A. M. (1959). Emotional and other selected characteristics of cigarette smokers and non-smokers as related to epidemiological studies of lung cancer and other diseases. Journal of the National Cancer Institute, 22, 259-282.
Mills, C. A. (1950). Tobacco smoking: some hints of its biologic hazards. Ohio State Medical Journal, 46, 1165-1170.

Monson, R. R. (1970). Cigarette smoking and body form in peptic ulcer. Gastroenterology, 58, 337-344.

Taylor, W. H. (1970). Pepsins of patients with peptic ulcer. Nature, 227, 76-77.

Toon, R. W., Cross, F. S., and Wangensteen, O. H. (1951). Effect of inhaled cigarette smoke on production of peptic ulcer in the dog. Proceedings of the Society for Experimental Biology and Medicine, 77, 866-869.

Trowell, O. A. (1934). The relation of tobacco smoking to the incidence of chronic duodenal ulcer. Lancet, 1, 808-809.

Walker, V., and Taylor, W. H. (1975). Pepsin inhibition in vivo and the therapeutic action of carbenoxolone. In Fourth Symposium on Carbonexolone, Edited by F. Avery Jones and D. V. Parke. pp. 55-59. Butterworths: London.

Walker, V., and Taylor, W. H. (1976). Pepsin 1 secretion in peptic ulcer and in stress (Abstract). Clinical Science and Molecular Medicine, 51, 14p.

Whitecross, D. P., Clarke, A. D., and Piper, D. W. (1974). The effect of cigarette smoking on human gastric secretion. Scandinavian Journal of Gastroenterology, 9, 399-403. 